\title{
An Investigation on Saros Bay Stationary Uncovered Pound Net (Dalian) Fishery
}

\author{
İsmail Çalışkan ${ }^{1}$, Adnan $\mathrm{Ayaz}^{2 *}$ \\ ${ }^{1}$ Çanakkale Onsekiz Mart Üniversitesi Fen Bilimleri Enstitüsü Su Ürünleri Avlama ve İşleme Teknolojisi ABD, Terzioğlu Yerleşkesi \\ 17020 Çanakkale, Türkiye \\ ${ }^{2}$ Canakkale Onsekiz Üniversitesi Deniz Bilimleri ve Teknolojisi Fakültesi, Terzioğlu Yerleşkesi 17020 Çanakkale, Türkiye \\ Correspondent: adnanayaz@comu.edu.tr \\ Received: 22.05.2020 Accepted: 12.06.2020 \\ Ismail Çalışkan: Orcid 0000-0002-3876-1038, Adnan Ayaz: Orcid 0000-0003-4839-9244
}

How to cite this article: Calıskan, İ., \& Ayaz, A., (2020). An investigation on Saros Bay stationary uncovered pound net (dalian) fishery. COMU J. Mar. Sci. Fish, 3(1): 11-18. DOI: 10.46384/jmsf.741425

\begin{abstract}
The study was carried out between April 2019 and September 2019 in order to examine the catch per unit effort, species size compositions and the net plans of the stationary uncovered pound nets (dalian) in Saros Bay. Since there is no land transportation to the dalians, the logistic needs of the dalian are made from the Ece Harbor, which is located within the borders of the Beşyol Village. Therefore, interviews with the owners of the dalians and the length measurements of the fish captured by the dalians were made in Ece Harbor. Before the fishing season, the technical plans of the nets were examined and their plans were drawn for the first time in Turkey. A total of 12 species belonging to 9 families were caught in three dalians during the 2019 fishing season. The catch per unit effort of the dalians were calculated as $53.9 \mathrm{~kg}^{-d a y^{-1}}$ for Arifağa Taşları, $52.6 \mathrm{~kg}^{-d a y^{-1}}$ for Bozburun and $43.2 \mathrm{~kg}$ day ${ }^{-1}$ for Mersinlik region. It was observed that the stationary uncovered pound net fisheries in Saros Bay did not catch significant amounts of undersized fish. Furthermore, the results have revealed that the net structures of stationary uncovered pound nets in Saros Bay should be modernized.* This research is a part of İsmail ÇALIŞKAN's MSc Thesis.
\end{abstract}

Keywords: Saros Bay, Dalian, Catch Per Unit Effort

\section{Saros Körfezi A ̆g Dalyan Balıkçılı̆̆ı Üzerine Bir İnceleme}

Özet: Çalışma Saros Körfezinde bulunan ağ dalyanların av verimleri, tür boy kompozisyonları ve ağ planlarının incelenmesi amacıyla Nisan 2019 - Eylül 2019 tarihleri arasında gerçekleştirilmiştir. Dalyanlara karadan ulaşım olmadığı için, dalyanların lojistik ihtiyaçları beşyol köyü sınırları içinde yer alan Ece Limanından yapılmaktadır. Çalışmada Ece limanına gidilerek dalyan sahipleri ile görüşmeler ve dalyanlardan gelen balıkların boy ölçümleri yapılmıştır. Sezon başlamadan önce dalyanda kullanılan ağların teknik planları incelenerek Türkiye'de ilk defa planlarının çizimi yapılmıştır. Çalışmada, 2019 balıkçılık sezonunda Saros Körfezi'nde incelenen 3 adet ağ dalyanda 9 familyaya ait 12 türün yakalandığı belirlenmiştir. İncelenen A ̆g dalyanların av verimleri Arifağa taşları mevkii için 53,9 kg/gün, Bozburun mevkii için 52,6 kg/gün ve Mersinlik bölgesi için 43,2 kg/gün olarak hesaplanmıştır. Araştırma sonucunda, Saros Körfezi'nde dalyanların yaptığı avcıllı̆ın yasal boy altı balıkları önemli derecede yakalamadığı görülmüsşür. Ek olarak, sonuçlar Saros Körfezi'ndeki dalyanlarının ağ yapılarının modernize edilmesi gerektiğini ortaya koymuştur. * Bu çalışma İsmail ÇALIŞKAN'ın yüksek lisans tezinden üretilmiştir.

Anahtar Kelimeler: Saros Körfezi, Ağ Dalyan, Av Verimi 


\section{Giriş}

Dünya balıkçılığında ağ dalyanlar ile avcılık en eski balıkçılık yöntemlerinden biridir. Uzakdoğu'da başlayıp, daha sonra batı ülkeleri tarafından benimsenmiş ve yaygınlaşmıştır (Bradford, 1971; Deveciyan, 2019; Suzuki ve Kai, 2012). Akdeniz'de eski zamanlardan itibaren özellikle ton balığ1 avcılığında kullanılmıştır (Bradford, 1971). Troia’nın güneybatısında bulunan Besik-Yassıtepe'deki ilk tunç çağına ait tabakalarda bulunan hayvan kalıntılarının büyük bir bölümünün orkinos balıklarına ait olduğu belirlenmiş ve bu balıkların büyük bölümünün dalyanlar tarafindan avlandığı tahmin edilmiştir (Bursa,2007 içinde Von den Driesch, 1996). Başbakanlık Osmanlı arşivlerinden (İ.MMS, 40/1655, 1287/1870) elde edilen bilgilere göre Bizans döneminde İstanbul Boğazı'nda basit dalyan faaliyetlerinin gerçekleştirildiğinden bahsedilmektedir. $\mathrm{Bu}$ dalyanların çitlerden ibaret olduğu ve balık bu çitlerin içine girdikten sonra çitin ağzının ağ ile kapatıldığı ve bu dalyanların sığ sularda kurulup çitlerin kalaslar ile desteklendiğinden bahsedilmektedir. $\mathrm{Bu}$ avcılığın benzer şekilde Osmanlı döneminde de devam ettiği bildirilmiştir (Doğan, 2011).

İlk zamanlar ağ dalyanlarda daha çok ton balıkları ve büyük pelajik balıkların avlandığı belirtilmiştir (Bradford, 1971). Muhtemel olarak eski dönemlerde teknolojinin olmamasından dolayı ağların el ile yapılması küçük göze sahip ağların yapılamamasından kaynaklanmış olabilir. 1820 yılında ağ düğümleme makinasının İskoçya'da keşfedilmesinden sonra ağ yapımı kolaylaşmış ve kendir kenevir lifleri yerine ağlarda pamuk lifleri kullanılmaya başlanmıştır. Bu tarihten sonra ağ yapımı kolaylaşmıştır (Sahrhage ve Lundbeck, 1992). Böylelikle daha küçük pelajik balıkların da yakalanması mümkün olmuştur. Nitekim Deveciyan (2019) Osmanlı İmparatorluğu'nun son dönemlerinde İstanbul Boğazı'nda kurulan ağ dalyanlarda gümüş balığının ağının bile kullanıldığını belirtmiştir. İstanbul Boğazı ve çevresinde daha çok balıkların göç yaptığı bölgelerde kurulan ağ dalyanların 1900'lü yıllarda sayılarının 52 adet olduğu bildirilmiştir (Deveciyan, 2019). Bu sayının 1960 yılında 17 adede (Yazıcı ve Öker, 1960), 2000 yılında 8 (Karakulak 2000) ve 2016 yılında 4 adede düştüğü bildirilmiştir (Yıldız ve Karakulak, 2016). Bu azalmanın sebebinin artan deniz trafiği, şehirleşme ve deniz kirliliğinden kaynaklandığı belirtilmiştir (Bök, 1991; Gabriel, Lange, Dahm ve Wendt, 2008; Y1ldız ve Karakulak, 2016).

Ağ dalyanların yaygın olarak kullanıldığ Çanakkale İli kıyılarında 19 adet dalyan bulunmaktadır. Bu dalyanların 3 adedi Çanakkale Boğazı'nda 15 adedi de Saros Körfezi'nde yer almaktadır. İstanbul ilinde sayıları yıllara göre azalmasına karşın, Çanakkale ilinde özellikle Saros
Körfezi'nde sayılarında ciddi bir artış olmuştur. Bu artış 2006 yılında durdurulmuştur.

Dünyanın en eski avcılık yöntemlerinden biri olmasına karşın, dalyanların avcılığı ile ilgili çok az yayına rastlanılmıştır. Bök (1991) Beykoz dalyanının işleyişi ve avcılığı üzerine bir tez çalışması; Çolakoğlu, Tokaç, İşmen ve Yurdusev (2015) Saros dalyanlarının 4 adedinde tür kompozisyonu ve av verimlerini, Biçer, Yıldız, Uzer, ve Karakulak (2020) ise İstanbul'da 4 adet ağ dalyanın tür kompozisyonu ve av verimi üzerine çalışmalar gerçekleştirmişlerdir.

Avcılık ile ilgili yapılan incelemelerde, dalyan ağının teknik planı incelenmemiş sadece kuşbakışı ve perspektif çizimlerinden başka bir araştırmaya rastlanılmamıştır (Bök, 1991; Biçer ve diğ., 2020; Çolakoğolu ve diğ., 2015; Deveciyan, 2019). Ayrıca dalyanlarda avlanan balıkların boy dağılımları ile ilgili de değerlendirmelere rastlanılamamıştır.

Saros Körfezi çabuk derinleşen kıyı yapısına sahiptir. Dalyan kurmaya son derece elverişli bir yapıda kısmen güneyli rüzgârlara kapalı bir yapısı vardır. Batı ve Karayele ise açıktır. Bundan dolayı kış mevsiminde bu rüzgârların fazla esmelerinden dolayı kış mevsiminde dalyan avcılığı Saros Körfezi'nde yapılamadığı dalyan balıkçıları tarafından ifade edilmektedir. Kış mevsiminde Çanakkale Boğazından çıkan balık sürülerinin bir kısmı, Gelibolu yarımadası kıyılarını takip ederek Yunanistan kıyılarına doğru göç yapmakta ancak bu mevsimde dalyanlar kurulu değildir. Balıkların Karadeniz'e tersine göçünde ise dalyanlar havalar sakinledikten sonra kurulduğu için yine av yapamamaktadır. Saros Körfezi Dalyanları, Nisan - Eylül ayları arasında kurulumu yapılmaktadır. Belirtilen aylar arasında daha çok balıkların günlük göçlerinden faydalanarak avcılık yapılmaktadır. Saros dalyanlarında daha çok, sardalya (Sardina pilchardus), iri sardalya (Sardinella aurita), istavrit (Trachurus sp.), kupez (Boops boops), izmarit (Spicara sp.), zargana (Belone belone) ve iskarmoz balığ1 (Sphyraena sphyraena) avcılığı yapılmakta olduğu bildirilmiştir (Çolakoğlu ve diğ., 2015). Bu çalışmada, Saros Körfezi'nde avcılık faaliyeti gösteren dalyanların av verimleri, tür boy kompozisyonları ve ağ planlarının incelenmesi amaçlanmıştır.

\section{Materyal ve Yöntem}

Araştırma Nisan 2019 - Eylül 2019 tarihleri arasında Saros Körfezi'nde gerçekleştirilmiştir. Araştırmanın materyalini Saros Körfezi'nde Arifağa taşları, Bozburun ve Mersinlik mevkilerinde faaliyet gösteren üç adet dalyan oluşturmaktadır. Bu dalyanların, bulunduğu mevkiler Şekil 1'de verilmiştir. Çalışmada incelenen dalyanların bulunduğu mevkilere karadan yol bulunmamaktadır. Bundan dolayı ağ dalyanlara ulaşım Çanakkale'nin Eceabat İlçesi Beşyol köyü sınırlarında yer alan Ece Limanı mevkiinden tekne ile sağlanmaktadır. 


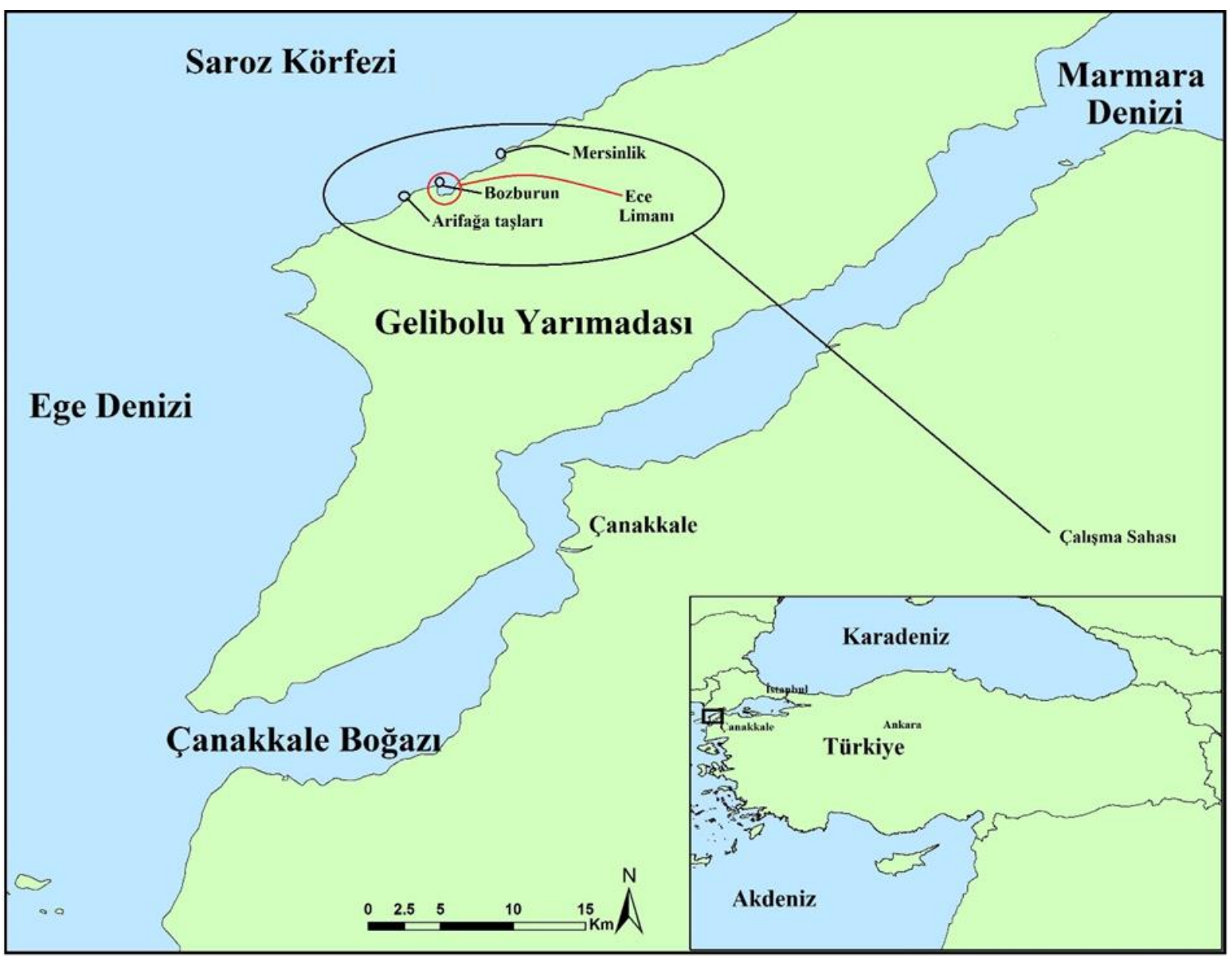

Şekil 1. Çalışma Sahası ((Arifağa Taşları: 40021'43,6”N, 026018'09,0”'E; 40021'45,6”N, 026018'12,4”'E; 4021'46,2”N, 026018'11,7'E; 40021'44,3”N,026018'08,3”E), (Bozburun: 42022'04,2”N, 026019'27,6”'E; $42^{0} 21^{\prime} 07,5$ ”N, $\left.026^{0} 19^{\prime} 27,2^{\prime \prime} \mathrm{E} ; \quad 42^{0} 22^{\prime} 04,2^{\prime \prime} \mathrm{N}, \quad 026^{0} 19^{\prime} 27,2^{\prime \prime} \mathrm{E} ; \quad 42^{0} 22^{\prime} 07,4^{\prime \prime} \mathrm{N}, \quad 026^{0} 19^{\prime} 26,1^{\prime \prime} \mathrm{E}\right)$, (Mersinlik: $40^{0} 21^{\prime} 09,8^{\prime \prime} \mathrm{N}, \quad 026^{0} 17^{\prime} 36,5^{\prime} \mathrm{E} ; \quad 40^{0} 21^{\prime} 11,2^{\prime \prime} \mathrm{N}, \quad 26^{0} 17^{\prime} 40,4^{\prime \prime} \mathrm{E} ; 40^{0} 21^{\prime} 11,9^{\prime} \mathrm{N}, \quad 026^{0} 17^{\prime} 39,9^{\prime \prime} \mathrm{E} ; \quad 40^{0} 21^{\prime} 10,6^{\prime} \mathrm{N}$, $\left.026^{0} 17^{\prime} 36,1 ’ \mathrm{E}\right)$ ).

Araştırmada, Ece Limanı mevkiine sabahın erken saatlerinde ulaşılmış, dalyan sahiplerinin balıklarını bu koya getirmeleri beklenmiştir. Burada yakalanan balıklardan rastgele örnek alınarak boy ölçümleri alınmıştır. Bunun yanında dalyan sahipleri ile görüşülerek durum hakkında bilgi alınmıştır. Çalışmada örneklemeler aylık olarak gerçekleştirilmiştir. Sezon sonunda incelenen üç dalyanın aylık olarak tür bazındaki üretim miktarlarının kayıtları dalyan sahiplerinden alınmıştır. Av verimleri 2019 sezonuna ait toplam üretim miktarlarının operasyon yapılan güz sayısına bölünmesi ile elde edilmiştir (Av verimi $(\mathrm{CPUE})=\mathrm{Bir}$ dalyanın toplam avı / Balıkçılık operasyonu sayısı). Yıllık av verimi ise üç dalyanın av verimi toplamının ortalaması alınmış ve 365 güne bölünmesi ile elde edilmiştir. Operasyon günü sayısı dalyanın kurulduğu bölgeye göre değişebilmektedir. $\mathrm{Bu}$ değişiklik dalyanın hakim rüzgarlara açıklık durumundan kaynaklı dalga ve akıntı durumuna göre değişmektedir. Farklı dalyanlardan alınan aylara göre üretim verilerine Bray-Curtis benzerlik analizi uygulanmış ve üretimin benzer olup olmadığına bakılmıştır. Ayrıca Avlanan türlerin birbirine aylık olarak benzer olup olmadıkları Anosim, farklılıklara neden olan türlerin farklılığa katkı oranları Simper analizi ile belirlenmiştir. Üç dalyanın üretim miktarları göz önünde bulundurularak, Saros dalyanlarının 2019 yılı içindeki toplam üretimleri için geniş bir tahminde bulunulmuştur.

Çalışmada, dalyan ağının planını sezon başlamadan önce bakım işlemi yapılırken incelenmiştir. Ölçüleri balıkçı tarafından kulaç olarak verilmiştir. Bu değerler göz genişliği göz önünde bulundurularak göz sayısına dönüştürülmüştür. Ağın planı donam faktörü esas alınarak ölçekli olarak çizilmiştir.

\section{Bulgular}

Çalışmada, sezon başlamadan önce ağların bakım işlemleri sırasında, ağlar incelenmiş ve planları çıkarılmıştır. Saros Körfezi'nde kullanılan dalyanının tuzak kısmının dış ve iç ağ olmak üzere iki farklı ağdan 
oluştuğu belirlenmiştir. Her iki bölümde $210 \mathrm{~d} / 6$ numara kalınlığında $10,5 \mathrm{~mm}$ göz genişliğine sahip ağ kullanılmıştır. Dişta bulunan ağ standart bir uzatma ağı olup su derinliğine göre yüksekliği ayarlanmaktadır. $\mathrm{Bu}$ ağın kurşun yakası dibe otururken mantar yakası suyun yüzeyine kadar gelmektedir. Bu ağda $E=0,50$ donam faktörü uygulanarak donam yapılmaktadır. Benzer durumun tuzak kısmına gelen kıyı germe ağında da aynı şekilde uygulanmakta olduğu belirlenmiştir. Dalyanın tamamında kullanılan ağın $210 \mathrm{~d} / 6$ numara ip kalınlığında $10,5 \mathrm{~mm}$ göz genişliğine sahip ağdan yapıldığı belirlenmiştir.

Dalyanın ebatları değişmekle birlikte, incelenen dalyanların 65 X 10 m olacak şekilde kazıklar ile sabitlendiği tespit edilmiştir. Kazıkların boyu su derinliğine göre ayarlanmakta çapı Şekil 2'de belirtildiği gibi $15 \mathrm{~cm}$ 'dir. Kuzey ve güney hattında (Lodos ve Poyraz hattı) bulunan direkler 3 er çapa ile diğerleri ise 1 er çapa ile sabitlenmiş ve hepsi birbirine su üzerindeki uzantılarından birbirine bağlanmıştır (Şekil 2). Direkler ile oluşturulan iskelete diş ağ dışarıdan tutturulmaktadır. Kıyıdan dalyanın tuzak kısmına gelen germe ağı da direklere bağlanmakta olup direklerin mesafesi 5 - $10 \mathrm{~m}$ olacak şekilde göz kararı ayarlanmakta olduğu belirlenmiştir. Bu direkler rüzgâr üstü ve altında 1 'er çapa ile sabitlenmekte ve su üzerindeki uzantıları da karadan itibaren birbirlerine bağlanarak sabitlendiği görülmüştür.

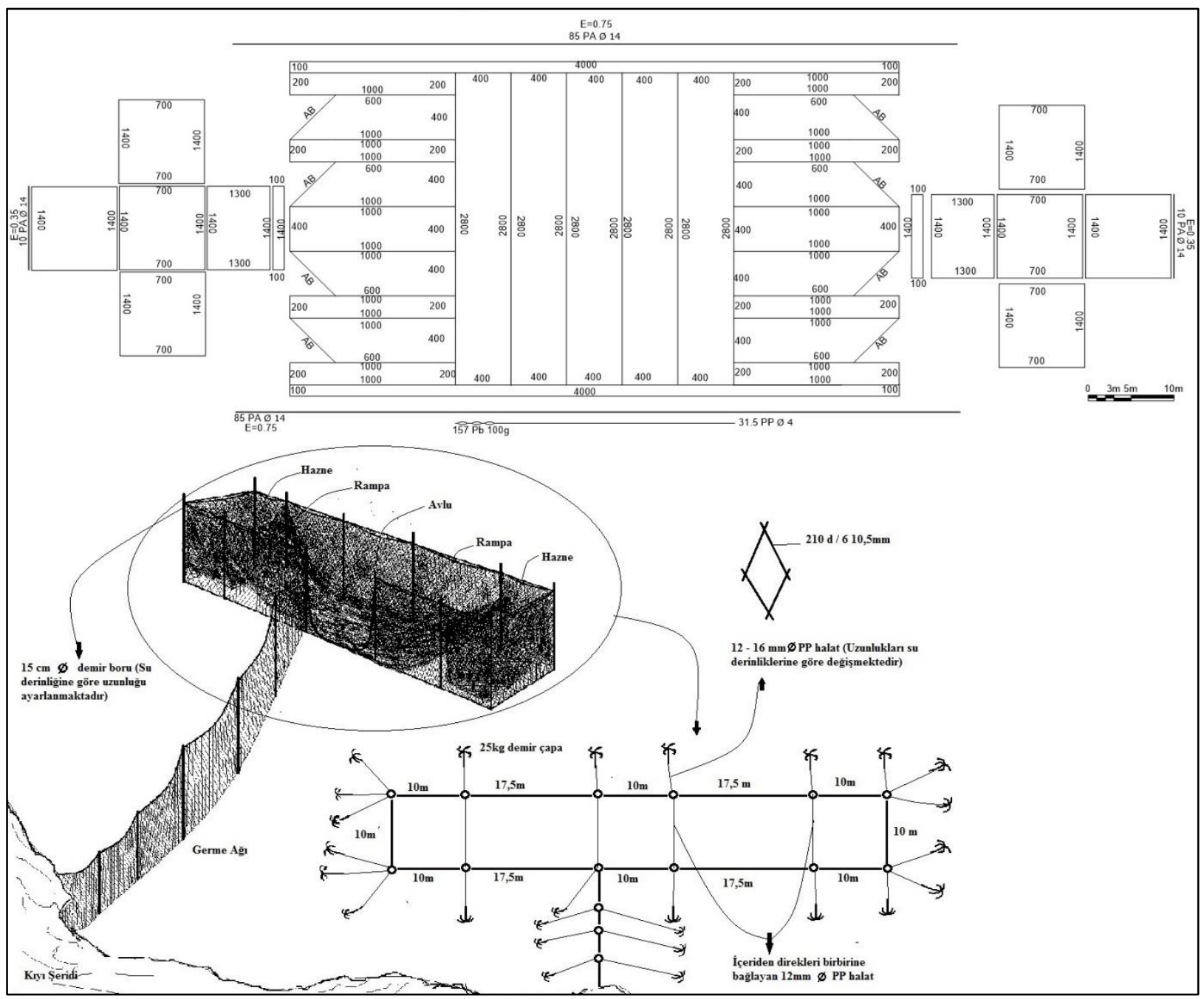

Şekil 2. Saros Körfezi’nde kullanılan Kurtağzı dalyanlarının genel planı

Dalyanda kullanılan iç ağın yapısı Şekil 2'de ölçekli olarak çizilerek gösterilmektedir. Dalyanın avlu kısmında 5 adet 400 X 2800 göz ebatlarında ağ parçaları kullanılmıştır. Dalyanın rampa kısmının 1000 X 400 göz ebatlarında olan bölümlerinde 400
X 400 ebatlarında üçgen parçalar kesim ile çıkartılarak daraltmalar yapılmış, bu parçaların arasına 1000 X 200 göz ebatlarında da dikdörtgen parçalar konulmuş ve birbirine bire bir olarak çatılarak donatım yapılmıştır (Şekil 2). Bu şekilde 
avlu bölümünden rampa bölümüne geçişte başlangıçtaki göz yüksekliği 2800 gözden 1400 göz yüksekliğine düşürülmüştür. Normalde 40 metre yükseklik açan avlu ve rampa bölümleri $10 \mathrm{~m}$ genişliğindeki dalyanın iskeletinin içine oturtulduğunda oluşan bolluktan dolayı, ağ yere oturmaktadır (Şekil 2). Dalyanın iskeleti incelendiğinde avlu ve rampa bölümlerinin uzunluğunun $45 \mathrm{~m}$ olduğu görülmektedir. Ancak buraya karşı gelen iç ağın donamdan sonraki uzunluğu ise 65 m gelmektedir. Bu fark, iç ağ dalyan iskelerinin içine oturtulurken dalyanın giriş bölümünün karşısında (Avlu bölümünde) büzülerek rampa bölümünün bire bir gerilmesi sağlanmakta ve giriş bölümünde ise ağzın donatılan kurşunlar yardımı ile yere oturarak açılmasını sağlamaktadır.

Balığın yakalandığı hazne bölümü $10 \times 10 \mathrm{~m}$ ebatlarında üstü olmayan bir küp şeklini andırmaktadır. $\mathrm{Bu}$ küp şekli oluşturulurken, bir tarafta $E=0,75$ donam faktörü uygulanmış, rüzgar üstü veya rüzgar altı yönlerindeki kenarlarda ise donam faktörü $\mathrm{E}=0,35$ olarak uygulanmıştır (Şekil 2). Rampa tarafındaki haznenin köşeleri kesilerek içeriye doğru yatırılmıştır. $\mathrm{Bu}$ durum haznenin rampa tarafından girişinde yaklaşık olarak $1 \mathrm{~m}$ yüksekliğinde bir su derinliği olmasını sağlamaktadır. $\mathrm{Bu}$ kısımın uçları karşı tarafa asılarak bağlanmıştır. Aynı zamanda bu parça haznenin içine giren balıkların kaçmasını engellemektedir.

Çalışmada dalyan sahipleri ile yapılan görüşmelerde, Arif Ağa Taşları mevkiindeki dalyanda toplamda sezon boyunca 117, Bozburun mevkiinde 123 ve Mersinlik mevkiinde 130 gün avcilık operasyonu gerçekleştirdiklerini belirtmişlerdir. Yapılan çalışmada bu dalyanlarda 2019 av sezonunda 9 familyaya ait 12 tür yakalandığ 1 belirlenmiştir. İncelemeye alınan üç dalyanın aylara göre yakalanan türlerin üretim miktarları Tablo 1'de verilmiştir. Üç dalyanın üretim miktarları incelendiğinde üretim miktarları arasında fazla fark olmadığ1 görülmektedir (Tablo 1). Dalyanların sezondaki av verimleri Arifağa taşları mevkii için $53,9 \mathrm{~kg} /$ gün, Bozburun mevkii için $52,6 \mathrm{~kg} /$ gün ve Mersinlik bölgesi için 43,2 kg/gün olarak hesaplanmıştır. Yıllık ortalama 3 dalyanın av verimi ise $16,794 \mathrm{~kg} / \mathrm{y}$ l olarak hesaplanmıştır. Dalyanlara önemli derecede yakalanan 6 tür sirası ile sardalye (Sardina pichardus) $(\% 41,6)$, kupes (Boops boops) (\%24,8), istavrit (Trachurus mediterraneus) (\%13), iri sardalye (Sardinella aurita) $(\% 6,25)$, İzmarit (Spicara maena) $(\% 6,58)$ ve 1 skarmoz (Sphyraena sphyraena) $(\% 5,27)$ olmuştur.

Dalyan sahipleri ile yapılan avcılık problemleri ile ilgili de ikili görüşmeler yapılmıştır. Saros dalyanlarında avcılıkta en büyük problemin hava koşullarına bağlı olarak, akıntının fazlalaşması ile artan akıntı olduğu belirtilmiştir. Bu akıntının ağı yukarıya kaldırarak av veriminin düşmesi veya dalyanın artan su direncinden yıkılmasına varan problemleri ortaya çıkardığı belirtilmiştir.

Dalyanlarda fazla yakalanan türlerin boy dağılımları rasgele örneklemeler ile elde edilmiş ve Şekil 3'te verilmiştir.

Bruy-Curtis benzerlik analizi sonucunda Bozburun mevkiinde bulunan dalyanın türlere göre av miktarların, Mersinlik ve Arifağa taşları mevkiinde bulunan ağ dalyanlar ile \%76, Mersinlik ve Arifağa taşları mevkiinde bulunan dalyanların birbirleri arasındaki benzerlik oranının \%82,5 oranında benzer bulunmuştur (Şekil 4). Buradan Saros Körfezi'nde faaliyet gösteren 15 adet dalyanın 2019 av sezonunda av miktarlarının 91,7-92,2 ton arasında değiştiği tahmin edilmiştir.

Tablo 1. Saros Körfezi’nde incelenen dalyanların av verimi (Ni: Nisan; Ma: Mayıs; Ha: Haziran; Tem: Temmuz; Ağu: Ağustos; Ey: Eylül. Üretim miktarları kg olarak verilmiştir.)

\begin{tabular}{|c|c|c|c|c|c|c|c|c|c|c|c|c|c|c|c|c|c|c|}
\hline \multirow{2}{*}{\begin{tabular}{|l} 
Ă̆ dalyanlar \\
Tür \\
\end{tabular}} & \multicolumn{6}{|c|}{ Arifağa Dalyanı } & \multicolumn{6}{|c|}{ Bozburun Dalyanı } & \multicolumn{6}{|c|}{ Mersinlik Dalyanı } \\
\hline & $\mathbf{N i}$ & Ma & Ha & Tem & Ăgu & Ey & $\mathbf{N i}$ & Ma & Ha & Tem & Ăğu & Ey & $\mathbf{N i}$ & Ma & Ha & Tem & Ăğu & Ey \\
\hline Sardalye (Sardina pilchardus) & 1500 & 1000 & & & & & 800 & 600 & 600 & 400 & 400 & & 900 & 500 & 200 & 170 & 200 & 380 \\
\hline Kupes (Boops boops) & 400 & 400 & 300 & 200 & 300 & 200 & & & 400 & 450 & 550 & 300 & 250 & 200 & 140 & 150 & 320 & \\
\hline İstavrit (Trachurus mediterraneus) & 100 & 200 & 100 & & & & 330 & 220 & 350 & 150 & 350 & & 140 & 300 & 70 & & 80 & \\
\hline İzmarit (Spicara maena) & 320 & 200 & & & & 100 & 240 & & & & & & 300 & & & & & 50 \\
\hline Zargana (Belone belone) & 1 & & & & 50 & & & & & & & & 1 & 1 & & & & \\
\hline Melanur (Oblada melenura) & & 5 & & & & & & & & & & & & & & & & \\
\hline Kefal (Mugil. Sp.) & & 1 & & & & & & & & & & & & & & & & \\
\hline Lüfer (Pomatamus saltatrix) & & & & & & & & 1 & & & & & & & & & & \\
\hline İri Sardalye (Sardinella aurita) & & & 150 & 300 & & & & & & & & & & & 250 & 250 & 150 & 50 \\
\hline Iskarmoz (Sphyraena sphyraena) & & & & 100 & 100 & 50 & & & & & & 250 & & & & 200 & 70 & 200 \\
\hline Sarpa (Sarpa salpa) & & & & 150 & & 50 & & & & & & & & & & 70 & & \\
\hline Kalamar (Loligo vulgaris) & & & & 30 & & & & & & & & 80 & & & & 10 & & 10 \\
\hline Toplam (kg) & 2321 & 1806 & 550 & 780 & 450 & 400 & 1370 & 821 & 1350 & 1000 & 1300 & 630 & 1591 & 1001 & 660 & 850 & 820 & 690 \\
\hline Toplam Av (kg) & & & & 307 & & & & & 64 & 171 & & & & & 561 & & & \\
\hline
\end{tabular}




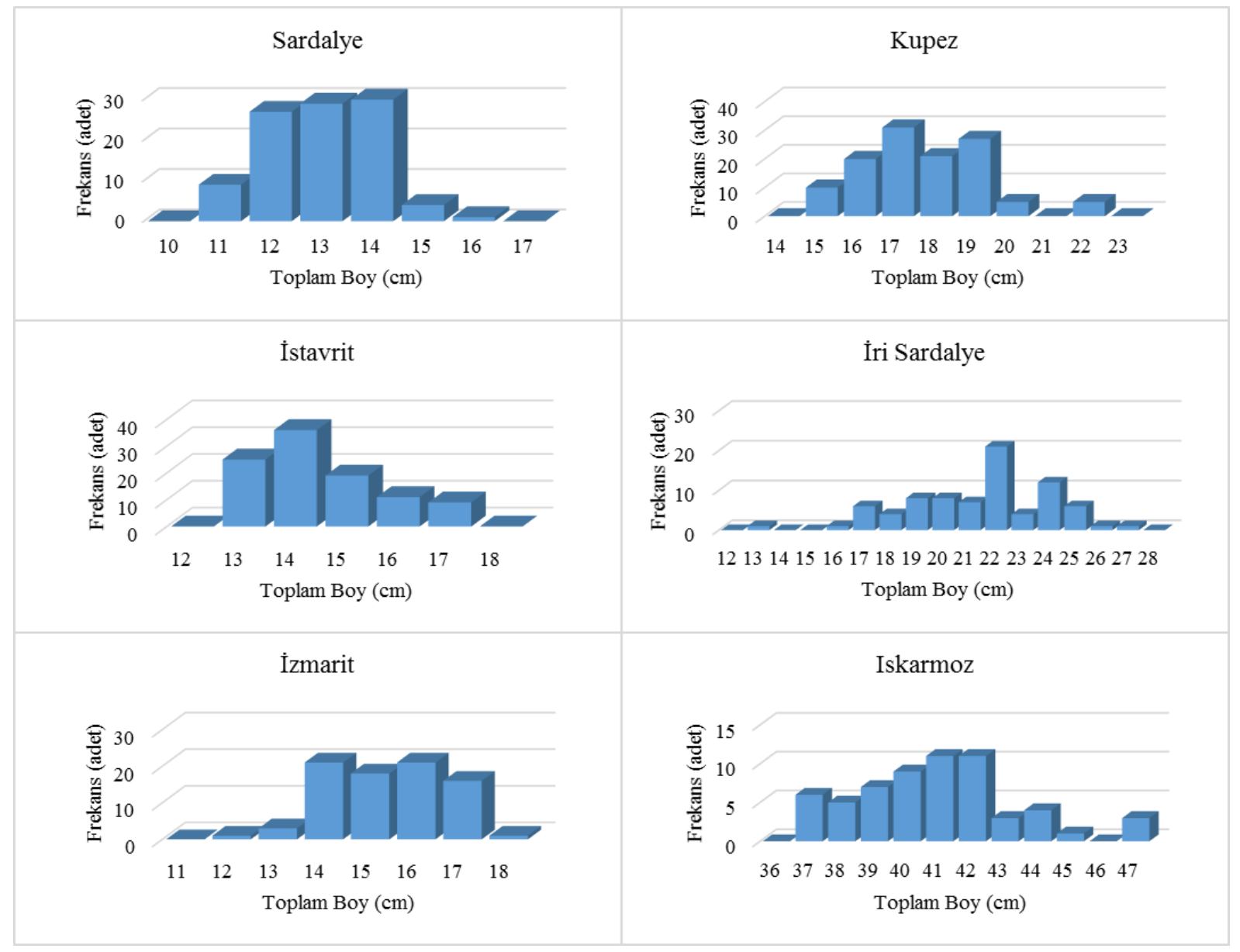

Şekil 3. Ağ dalyanlara önemli derecede yakalanan balıkların boy dağılımları (her bir türden rastgele 100 adet türün boy ölçümü yapılmıştır).

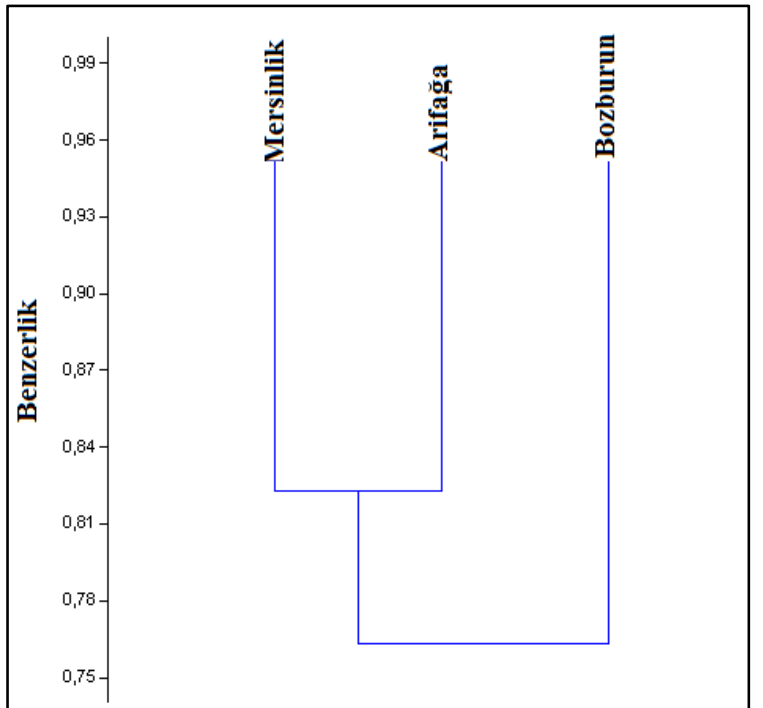

Şekil 4. Bruy-Curtis analiz sonuçları

Dalyanlarda avlanan türlerin aylara göre benzerlikleri arasında farklılıklar olduğu benimsenmiştir $(P<0.05 ; R=0,22)$. Dalyanların av türlere göre av miktarları arasında farklılığa katkı sağlayan türler Simper analizi ile belirlenmiştir. Arifağa taşları mevki ile Bozburun mevkii arasındaki farkl1lığa en fazla katk1 sağlayan türler sardalye (\%43), kupez (\%19) ve iri sardalye (\%15) olmuştur. Arifağa taşları ile Mersinlik mevkiileri arasındaki farklılığa sardalye (\%43), iri sardalye (\%13) ve kupez (\%13) katk1 sağladığı belirlenmiştir. Bozburun ve mersinlik dalyanları arasında ise sardalye (\%28), kupez (\%24) ve istavrit (\%18) farklılığa en fazla katkı sağlayan türler olmuştur

\section{Tartışma ve Sonuç}

Tuzak bölümünün teknik planının ilk kez çizildiği çalışmada dalyan ağının yapısı incelenmiştir. Deveciyan (2019) dalyanları şıra, kurtağzı, kırmakepasti, çekme ve çökertme olarak 5 gurupta ele almıştır. Yapılan incelemede Saros Körfezi'nde kullanılan dalyan tipinin bünyesinde çift hazne bulundurmasından dolayı kurtağzı tipinde olduğu belirlenmiştir. Önceki çalışmalara (Bök, 1991; Gabriel ve diğ., 2008; Çolakoğolu ve diğ., 2015; Yıldız ve Karakulak, 2016; Deveciyan, 2019; Biçer ve diğ., 2020) bakıldığında dalyanların sadece kuşbakışı planlarına ve perspektif çizimlerine yer verildiği belirlenmiş̧tir. Ağın yapısı incelendiğinde, ağda çok fazla gereksiz ağ kullanımı yapıldığı görülmüştür. Modern kesim teknikleri uygulanarak bu ağın yeniden yapılması akıntı probleminin de bertaraf edilmesini sağlayabilecektir. 
Dalyanların av verimleri incelendiğinde mevkilere göre çok fazla farklılıklar göstermiştir. Bu durum dalyan mevkilerinin birbirine yakın olmasından kaynaklanmış olabilir. Nitekim Çolakoğlu ve diğg. (2015) dalyanların üç yıllık av verimlerini incelemiş ve avlarında oldukça fazla farlılık olduğunu gözlemlemiştir. Çalışmada inceledikleri dalyanlar arasındaki mesafenin bizim dalyanlarımıza göre çok daha fazla olduğu görülmüştür. Biçer ve diğ. (2020) İstanbul Boğazı'nda kurulan üç dalyanı inceledikleri çalışmalarında av gününü 36, 24 ve 37 gün olduğunu bildirmişlerdir. Çalışmamızda ise av günü belirtilen rakamlardan yaklaşık üç buçuk kat daha fazla olduğu görülmüştür. Bu duruma İstanbul dalyanlarının av sezonunun k1sa olması (Nisan- Haziran) neden olmuştur. İstanbul dalyanları iki ay kurulu dururken, Saros dalyanları yaklaşık altı ay (Nisan - Eylül) kurulu kalmaktadır.

İncelemede dalyanlara en fazla yakalanan türler incelendiğinde, altı adet türün önemli derecede yakalandığı görülmüştür. Benzer şekilde Çolakoğlu ve di ̌̆. (2015) de bu türlerin dalyanların av veriminde önemli derecede yer tuttuğunu belirtmiştir. Çalışmamızda dalyanlara 9 familyaya ait 12 tür yakalandığı belirlenmiştir. Çolakoğlu ve diğ., (2015) ise 23 familyaya ait 39 tür yakalandığı bildirilmiştir. Denemelerde örneklemeler aylık olarak yapıldı tesadüfen yakalanan türler, veriler dalyan sahiplerinden alındığ 1 için belirlenememiş olabilir. Çolakoğlu ve diğ., (2015) yaptığı çalışmada da tesadüfen yakalanan türlerin birkaç adet olduğu görülmektedir.

Denemelerde rastgele örneklemeler yapılarak balıkların boy ölçümleri yapılmıştır. Bu ölçümler sonucunda sardalye (Sardina pilchardus) $11-15 \mathrm{~cm}$, kupez (Boops boops) $15-20 \mathrm{~cm}$, istavrit (Trachurus mediterraneus) $13-17 \mathrm{~cm}$, iri sardalye (Sardinella aurita) $17-25 \mathrm{~cm}$, izmarit (Spicara maena) $13-17$ $\mathrm{cm}$ ve 1skarmoz (Sphyraena sphyraena) balıklarının $37-47 \mathrm{~cm}$ arasında dalyanlara yakalandığı belirlenmiştir. Tablo 2'de bu türler için belirlenen ilk üreme boyları ve yasal yakalama boyları verilmiştir. Boylar incelendiğinde dalyanlara yakalanan sardalyenin \%9'u, iri sardalyenin \%0,25'i, izmaritin ise $\% 0,26$ 'sının ve toplam yakalanan balıkların \%9,94'ünün ilk üreme boyunun altında olduğu belirlenmiştir. Yaz sezonunda av gerçekleştirilen Saros dalyanlarının avcılığının türlerin devamlılığı açısından çok fazla sıkıntı yaratmadığı görülmüştür.

Tablo 2. Çalışmada en fazla yakalanan türlerin ilk üreme ve yasal yakalama boyları (Boylar cm olarak verilmiştir.)

\begin{tabular}{|c|c|c|c|c|c|}
\hline \multirow[b]{2}{*}{ Tür } & \multirow{2}{*}{$\begin{array}{c}\text { Yasal } \\
\text { Yakalama } \\
\text { Boyu }\end{array}$} & \multicolumn{2}{|c|}{ İlk Üreme Boyu } & \multirow[b]{2}{*}{ Bölge } & \multirow[b]{2}{*}{ Kaynak } \\
\hline & & Dişi & Erkek & & \\
\hline Sardalye (Sardina pilchardus) & 11 & 11,65 & 11,37 & Ege Denizi & Tsikliras ve Koutrakis (2013) \\
\hline Kupez (Boops boops) & -- & 13 & 9,4 & Ege Denizi & Kınacıgil ve diğ. (2008) \\
\hline İstavrit (Trachurus mediterraneus) & 13 & 12,2 & 12,5 & $\begin{array}{c}\text { Marmara ve } \\
\text { Batı Karadeniz }\end{array}$ & Demirel ve Yüksek (2008) \\
\hline İri sardalye (Sardinella aurita) & 11 & 16,8 & 15,5 & Ege Denizi & Tsikliras ve Antonopoulou (2006) \\
\hline İzmarit (Spicara maena) & -- & 11,5 & 13,1 & Ege Denizi & Kınacıgil ve diğ. (2008) \\
\hline Iskarmoz (Sphyraena sphyraena) & -- & 27,6 & 26,7 & $\begin{array}{c}\text { Güney Doğu } \\
\text { Akdeniz }\end{array}$ & Allam ve diğ. (2004) \\
\hline
\end{tabular}

Anosim ve Simper analizi sonuçları, dalyanların aylara göre farklı türleri avladığını göstermiştir $(P<0.05 ; \quad R=0,22)$. Bu duruma dalyanın derin bölgeye yakınlık ve akıntı etkisi gibi kurulum yeri özelliklerinin neden olduğu düşünülmektedir.

Araştırma sonucunda, Saros körfezi dalyanlarının önemli derecede yakaladıkları balık türleri göze alındığında, stoklara herhangi bir baskı oluşturmadığı

\section{Kaynaklar}

Allam, S. M., Faltas, S. N., \& Ragheb, E. 2004. Reproductice biology of Sphyraena species in the Egyptian Mediterranean waters off Alexandria. Egyptian Journal of Aquatic Research. 30 (B): 255-270 görülmüştür. Bundan başka sonuçlar Saros Körfezi dalyanlarının ağ yapılarının elden geçirilmesi gerektiğini ortaya koymuştur. Ağların modernize edilmesi dalyanların daha az su direncine maruz kalmasını, daha fazla av günü kazanmalarını ve daha az ağ maliyeti ile işletilmelerini sağlayacaktır.

Biçer, D., Yıldız, T., Uzer, U., \& Karakulak, S. 2020. İstanbul Boğazı'nda kurulan son dalyanlar: Av kompozisyonu birim av gücü ve bazı ekolojik indeksler. Ege Journal of Fisheries and Aquatic Sciences, 37(2), 125-133. DOI: 10.12714/egejfas.37.2.02

Bök, T. (1991). Beykoz Dalyanı'nın İşleyişi ve Avcılığı Üzerine Araştırmalar, İstanbul Üniversitesi, Fen Bilimleri Enstitüsü, Yüksek Lisans Tezi, s. 61, İstanbul. 
Bradford, E. 1971, Mediterranean: portrait of a sea, Penguin, 573p, ISBN: 9780151585847

Bursa, P. (2007). Antikçă̆'da Anadolu'da Balık ve Balıkçılık, İÜ Sosyal Bilimler Enstitüsü, Doktora Tezi, s. 271, İstanbul.

Çolakoğlu, S., Tokaç, A., İşmen, A., \& Yurdusev, H. (2015). Catch composition of set net (fixed stake trap) fisheries in the coastal waters of Saros Bay, North Aegean Sea. Ege Journal of Fisheries and Aquatic Sciences, 32(2), 53-58. DOI: 10.12714/egejfas.2015.32.2.01

Deveciyan, K., 2019. Türkiye'de Balık ve Balıkçlık. Aras Yayıncılık 7. bask1, İstanbul. 574s.

Demirel, N. \& Yüksek, A. 2013. Reproductive biology of Trachurus mediterraneus (Carangidae): A detailed study for the MarmaraBlack Sea stock. Journal of the Marine Biological Association of the United Kingdom, 93(2), 357364. doi:10.1017/S0025315412001014

Doğan, F. (2011). Osmanlı'da Boğaziçi’nde Balıkçılık (18.Yüzyıl-20.Yüzyıl). Tarih Okulu, Mayıs-Ağustos Sayı X: 39-57.

Gabriel, O., Lange, K., Dahm, E., \& Wendt, T. (Eds.) 2008. Von Brandt's Fish catching methods of the world. Blackwell, Oxford, UK, 536 pp.

Karakulak, F.S. (2000). İstanbul Boğazı ve civarındaki ăg dalyanlarl, Öztürk, B., Kadığlu, M., Öztürk, H. (Eds.), "Marmara Denizi 2000" Sempozyumu, 11-12 Kasım 2000, Türk Deniz Araştırma Vakfı Yayınları No. 5, s. 426-435, İstanbul.

Kınacıgil, H.T., İlkyaz, A.T., Metin, G., Ulaş, A., Soykan, O., Akyol, O., \& Gurbet, R. 2008. Balıkçılık Yönetimi Açısından Ege Denizi Demersal Stoklarının İlk Ürüme Boyları, Yaşları ve Parametrelerinin Tespiti. TÜBITTAKÇAYDAG Proje No: 103Y132, 327p.

Sahrhage, D. \& J. Lundbeck. 1992. History of fishing. Springer-Verlag Berlin Heidelberg, Germany. $348 \mathrm{p}$.

Suzuki, Z. \& Kai, M. (2012). General information on Japanese trap fisheries catching Pacific bluefin tuna (Thunnus orientalis): Fishery and socio economics. Collective Volumes of Scientific Papers ICCAT, 67(1), 361-371.

Tsikliras, A. \& Antonopoulou, E., 2006. Reproductive biology of round sardinella (Sardinella aurita) in the north-eastern Mediterranean. Scientia Marina, 70(2): 281-290.

Tsikliras, A. C. \& Koutrakis E. T., 2013. Growth and reproduction of European sardine, Sardina pilchardus (Pisces: Clupeidae), in northeastern Mediterranean. Cahiers de Biologie Marine, 54:365-374.
Yazıc1, S.A. \& Öker, A. (1960). Boğaziçi ve Civarı Dalyanları Hakkında Tetkikler (Kısım I). Balık ve Balıkçılık Dergisi, VIII (7), 19-22.

Yıldı, T. \& Karakulak, F.S. (2016). Traditional Fishing in the Marmara Sea. The Sea of Marmara; Marine Biodiversity, Fisheries, Conservation and Governance, Özsoy, E., Çağatay, M.N., Balkıs, N., Balkıs, N., Öztürk, B. (Eds.) Turkish Marine Research Foundation (TÜDAV), Publication No: 42, pp. 697-709, ISBN 978-975-8825-34-9, Istanbul. 